\title{
HUBUNGAN AKTIVITAS FISIK DENGAN KEJADIAN KONSTIPASI PADA LANSIA DI KOTA MADIUN
}

\author{
Amelia Dyah Kartika Sari' ${ }^{1}$, Bambang Wirjatmadi ${ }^{2}$ \\ 1,2Departemen Gizi Kesehatan, Fakultas Kesehatan Masyarakat, Universitas Airlangga \\ Kampus C Unair Jalan Mulyorejo Surabaya \\ Email: dyah.amelia96@gmail.com
}

\begin{abstract}
ABSTRAK
Lanjut usia (lansia) adalah tahap akhir dalam kehidupan manusia yang pada umumnya dimulai pada usia 60 tahun. Fase lansia ditandai dengan penurunan fungsi tubuh sehingga rentan terhadap penyakit. Salah satu penyakit yang sering dialami lansia adalah konstipasi. Konstipasi dapat disebabkan oleh berbagai faktor, salah satunya adalah kurangnya aktivitas fisik. Tujuan penelitian ini adalah untuk menganalisis hubungan aktivitas fisik dengan kejadian konstipasi pada lansia. Populasi sasaran adalah lansia di Kota Madiun. Subjek penelitian diambil menggunakan teknik cluster random sampling dan simple random sampling dengan besar sampel 68 orang lansia yang dinilai aktivitas fisiknya selama satu minggu menggunakan kuesioner Physical Activity Scale for Elderly dan ditentukan kejadian konstipasinya melalui kuesioner Constipation Scoring System. Analisis statistik dilakukan dengan uji Korelasi Spearman. Hasil penelitian menunjukkan bahwa sebagian besar (73,5\%) responden memiliki aktivitas fisik yang rendah dan sebanyak 66,2\% dari total responden mengalami konstipasi. Terdapat hubungan yang kuat dan bersifat positif antara aktivitas fisik dengan kejadian konstipasi pada lansia $(\mathrm{p}=0,000, \mathrm{r}=0,557)$. Kesimpulan penelitian ini adalah lansia di Kota Madiun yang cukup melakukan aktivitas fisik cenderung tidak terkena konstipasi.
\end{abstract}

Kata kunci: aktivitas fisik, konstipasi, lansia

\section{ABSTRACT}

Elderly is the final stage in human life which usually begins at age 60 years. Elderly phase characterized by decreased function of the body and more susceptible to diseases. One of the disease that are often experienced by the elderly is constipation. Constipation can be caused by various factors, one of which is lack of physical activity. The purpose of this study was to analyze the correlation between physical activity and constipation in Madiun City elderly. The subject, which collected using cluster random sampling and simple random sampling method, was 68 elderly which a week physical activity were scored using Physical Activity Scale for the Elderly questionnaire and constipation rate analyzed by Constipation Scoring System questionnaire. Statistic analysis was done using Spearman Correlation test. Results showed that the majority (73.5\%) of respondents did not do enough physical activity, and as much as $66.2 \%$ of total respondents had constipation. There was a strong and positive correlation between physical activity and constipation in elderly ( $p=0.000 ; r=0.557)$ The conclusion of this study is that elderly in Madiun City who did enough physical activity tend to not have constipation.

Keywords: physical activity, constipation, elderly

\section{PENDAHULUAN}

Salah satu pencapaian suatu negara adalah tercapainya keberhasilan pembangunan yang dilihat dari peningkatan usia harapan hidup. Peningkatan usia harapan hidup berbanding lurus dengan peningkatan jumlah lansia. Pada tahun 2010, jumlah lansia di Indonesia sebanyak 18.043.712 jiwa atau 7,59\% dari total penduduk (Badan Pusat Statistik, 2010). Sedangkan pada tahun 2014, jumlah lansia di Indonesia mencapai
20,24 juta jiwa atau $8,03 \%$ dari total penduduk Indonesia dan diperkirakan angka tersebut akan terus meningkat setiap tahunnya (Badan Pusat Statistik, 2014). WHO menyatakan bahwa penduduk lansia di Indonesia diperkirakan akan mencapai $11,34 \%$ dari total populasi pada tahun 2020 atau sekitar 28,8 juta orang sehingga mengakibatkan Indonesia memiliki jumlah lansia terbanyak di dunia (Solikhah, 2011). Namun, meningkatnya jumlah lansia berarti meningkat juga kemungkinan naiknya kasus penyakit degeneratif, 
seperti penyakit jantung, hipertensi, gangguan gastrointestinal hingga konstipasi (Yang, et al., 2012). Munculnya penyakit degeneratif ini dapat disebabkan oleh berbagai faktor, seperti usia, pola makan, dan pola hidup (frekuensi olahraga, dan lain sebagainya) (Marjan, et al., 2013).

Konstipasi adalah kondisi di mana feses mengeras sehingga susah dikeluarkan melalui anus, dan menimbulkan rasa terganggu atau tidak nyaman pada rektum (Brown, 2011). Konstipasi dapat terjadi pada semua lapisan usia, yang pada umumnya ditandai dengan frekuensi buang air besar yang rendah (kurang dari 3 kali dalam satu minggu).

Konstipasi masih sering dianggap remeh oleh masyarakat. Mereka menganggap kesulitan buang air besar bukan masalah besar, hanya akibat dari salah makan atau kurang minum air sehingga disepelekan dan dianggap akan sembuh dengan sendirinya. Padahal, konstipasi dapat mengakibatkan kanker usus besar (colon cancer) yang dapat berujung pada kematian (Brown, 2011).

Prevalensi konstipasi pada lansia di Indonesia adalah sebesar 3,8\% untuk lansia usia 60-69 tahun dan $6,3 \%$ pada lansia diatas usia 70 tahun (Kemenkes RI, 2013). Konstipasi dapat disebabkan oleh berbagai hal, seperti kurangnya asupan serat, kurang asupan air, pengaruh obat yang dikonsumsi, pengaruh dari penyakit yang diderita, hingga akibat kurang aktivitas fisik (Brown, 2011).

Banyak penelitian yang telah dilakukan untuk mengetahui penyebab terjadinya konstipasi, terutama asupan serat dan asupan air. Akan tetapi belum banyak penelitian yang meneliti hubungan aktivitas fisik dengan kejadian konstipasi. Aktivitas fisik itu sendiri memiliki pengertian serangkaian gerakan fisik yang dilakukan oleh otot tubuh dan sistem penunjangnya (Almatsier 2003 dalam Azizah 2014).

Menurut Pratiwi, et al. (2013), pola aktivitas fisik lansia di Indonesia sebagian besar dihabiskan pada kegiatan ringan dalam rumah seperti menonton TV, tidur, bersantai dengan keluarga, dan sejenisnya. Sebagian lansia masih melaksanakan aktivitas yang bersifat sedang seperti membersihkan rumah dan kegiatan di luar rumah seperti pergi ke pasar, mengikuti perkumpulan lansia dan lain sebagainya. Akan tetapi hanya sekitar $10 \%$ dari total lansia di Indonesia yang masih aktif dan rutin melakukan olahraga untuk menjaga kebugaran tubuh. Sedangkan beberapa lainnya hanya pernah melakukan sekali atau dua kali dalam sebulan, lebih karena ada kegiatan tertentu, contohnya acara jalan sehat.

Nugroho (2014) melakukan penelitian tentang aktivitas fisik, konstipasi, dan derajat hemoroid. Akan tetapi penelitian yang dilakukan oleh Nugroho (2014) tidak menitikberatkan pada hubungan aktivitas fisik dengan konstipasi, tetapi meneliti hubungan keduanya dengan derajat hemoroid. Hanya saja di dalam penelitiannya disebutkan bahwa ada kemungkinan aktivitas fisik berhubungan dengan konstipasi, tanpa ada penelitian lebih lanjut. Selain itu, penelitian tersebut tidak spesifik meneliti konstipasi pada lansia.

Di beberapa negara maju telah banyak dilakukan penelitian tentang konstipasi pada lansia dan kaitannya dengan penyakit degeneratif, terutama kanker usus besar. Peneliti menganggap bahwa konstipasi adalah masalah yang serius, karena dengan gaya hidup masyarakat yang terus berubah mengikuti arus globalisasi, bukan tidak mungkin bahwa konstipasi akan menjadi masalah yang perlu diperhatikan di kemudian hari. Oleh karena itu, perlu dilakukan penelitian untuk mengetahui lebih lanjut apakah terdapat hubungan antara aktivitas fisik dengan kejadian konstipasi pada lansia. Peneliti tertarik untuk melakukan penelitian pada lansia di Kota Madiun. Selain karena Kota Madiun merupakan kota kecil yang memiliki jumlah lansia yang cukup besar dan terus meningkat setiap tahunnya, di Kota Madiun juga belum pernah dilakukan penelitian tentang konstipasi pada lansia.

Tujuan dari penelitian ini adalah untuk menganalisis hubungan antara aktivitas fisik dengan kejadian konstipasi pada lansia di Kota Madiun.

\section{METODE}

Desain penelitian yang digunakan dalam penelitian ini adalah cross sectional. Penelitian dilakukan di Kota Madiun pada bulan April 2016, 
dengan sasaran populasi adalah seluruh lansia di Kota Madiun. Besar sampel minimal adalah 68 orang. Besar CI adalah $90 \%$ dan $\alpha=0,1$, dipilih karena keterbatasan peneliti (semakin besar CI atau semakin kecil $\alpha$ maka besar sampel akan meningkat). Kriteria inklusi yang ditetapkan adalah lansia berusia minimal 60 tahun, memiliki kartu tanda penduduk (KTP) sebagai penduduk Kota Madiun, bersedia menandatangani pernyataan persetujuan menjadi responden dan harus dalam keadaan sadar, dan mampu diajak berkomunikasi dengan baik.

Pengambilan sampel dilakukan dengan menggunakan metode cluster random sampling dan simple random sampling. Kota Madiun dibagi dalam 3 cluster yang dibagi berdasarkan kecamatan untuk kemudian dipilih melalui undian, cluster terpilih ditetapkan sebagai cluster1. Dari cluster 1 kemudian dilakukan lagi pengelompokan menjadi 9 cluster, berdasarkan 9 kelurahan, untuk diundi dan menentukan cluster2. Dari cluster2 kemudian pemilihan responden ditentukan melalui simple random sampling melalui data lansia yang didapat dari seluruh ketua RT di cluster2.

Semua lansia yang memenuhi kriteria inklusi dicatat identitasnya sebagai responden. Kemudian setiap responden diwawancara tentang aktivitas fisiknya selama satu minggu terakhir dengan menggunakan kuesioner Physical Activity Scale for Elderly (PASE). Pada saat yang sama responden juga diwawancarai tentang konstipasi menggunakan kuesioner Constipation Scoring System. Kegiatan wawancara dilakukan satu kali untuk mendapat informasi tentang aktivitas fisik dan konstipasi di waktu yang bersamaan. Pengisian kuesioner dilakukan oleh peneliti.

Kemudian, masing-masing kuesioner responden dihitung total nilainya sebagai acuan dalam mengkategorikan aktivitas fisik dan konstipasi pada responden. Bagi responden yang nilai aktivitas fisiknya di bawah nilai median dari seluruh responden (nilai median responden $=21,8$ ), dikategorikan kurang beraktivitas dan sebaliknya jika total nilai aktivitas fisik diatas median, maka dikategorikan sebagai cukup beraktivitas, penilaian dilakukan dengan menggunakan teknik penilaian yang dilakukan oleh Washburn, et al. (1993).
Untuk nilai konstipasi, rentang nilai sebesar 0-30. Di dalam kuesioner CSS, terdapat 8 pertanyaan, yang mana ada 7 pertanyaan dengan nilai maksimal 4, dan 1 pertanyaan dengan nilai maksimal 2. Bagi responden yang memiliki total nilai konstipasi di atas 15 dikategorikan mengalami konstipasi, sedangkan responden dengan nilai konstipasi di bawah 15 dikategorikan tidak mengalami konstipasi (Agachan, et al., 1996). Data yang telah dikumpulkan kemudian dianalisis secara statistik menggunakan uji Korelasi Spearman.

\section{HASIL DAN PEMBAHASAN}

\section{Gambaran Umum Lokasi}

Penelitian ini berlokasi di Kelurahan Nambangan Kidul, Kecamatan Manguharjo, Kota Madiun, sebagai cluster 2 yang dipilih berdasarkan undian. Responden dipilih dengan metode simple random sampling dari setiap RT yang berada di wilayah kerja Kelurahan Nambangan Kidul dan kemudian proses wawancara dilakukan di rumah masing-masing responden dan di balai posyandu lansia.

\section{Karakteristik Responden}

Terdiri dari jenis kelamin, usia, dan pekerjaan. Berdasarkan Tabel 1, dari semua responden terdapat 30,9\% responden laki-laki dan $69,1 \%$ responden perempuan. Berdasarkan penelitian, responden perempuan cenderung memiliki variasi kegiatan sehari-hari yang lebih tinggi, meskipun aktivitas fisik yang dilakukan sebagian besar

Tabel 1. Distribusi Karakteristik Responden

\begin{tabular}{lrr}
\hline \multicolumn{1}{c}{ Jenis Karakteristik } & n & \% \\
\hline Jenis Kelamin & & \\
$\quad$ Laki-laki & 21 & 30,9 \\
$\quad$ Perempuan & 47 & 69,1 \\
Usia & & \\
$\quad$ Usia Lanjut & 49 & 72,1 \\
$\quad$ Usia Tua & 17 & 25,0 \\
$\quad$ Usia Sangat Tua & 2 & 2,9 \\
Pekerjaan & & \\
$\quad$ Pensiunan PNS & 5 & 7,4 \\
$\quad$ Swasta/Wiraswasta & 22 & 32,4 \\
$\quad$ Buruh & 2 & 2,9 \\
$\quad$ Tidak Bekerja & 39 & 57,4 \\
\hline Total & 68 & 100,0 \\
\hline
\end{tabular}


merupakan aktivitas fisik yang ringan dan sedang, seperti membersihkan rumah, memasak, menjaga cucu, mengobrol dengan tetangga, menjaga toko dan lain sebagainya.

Penelitian ini khusus meneliti lansia (berusia diatas 60 tahun) sehingga penggolongan usia dilakukan menjadi usia lanjut (60-75 tahun), usia tua (76-90 tahun), dan usia sangat tua (diatas 90 tahun) (Adriani \& Wirjatmadi, 2012). Berdasarkan Tabel 1, jumlah responden yang tergolong usia lanjut sebesar 72,1\%, 25\% tergolong usia tua dan hanya $2,9 \%$ yang tergolong dalam usia sangat tua.

Faktor usia berpengaruh terhadap aktivitas fisik yang dilakukan oleh responden. Semakin tua usia responden, maka akan cenderung lebih sedikit melakukan aktivitas fisik. Hal tersebut dapat disebabkan oleh tingkat ketahanan tubuh yang semakin menurun seiring bertambahnya usia atau dapat juga disebabkan penurunan variasi dan jumlah kegiatan yang dapat dilakukan (Solikhah, 2011). Contohnya saat memasuki masa lansia, responden mengalami pensiun sehingga apabila sehari-hari responden biasa menghabiskan waktu untuk bekerja, setelah pensiun responden cenderung menghabiskan waktu di dalam rumah.

Banyaknya aktivitas fisik yang dilakukan dapat dipengaruhi oleh jenis pekerjaan yang dilakukan. Sebagian besar responden sudah tidak bekerja $(57,4 \%), 32,4 \%$ masih bekerja swasta/ wirausaha dengan berdagang, sisanya bekerja sebagai buruh sebesar 2,9\% dan pensiunan PNS sebesar 7,4\%. Responden yang masih bekerja pada umumnya cenderung melakukan aktivitas fisik yang lebih banyak dibandingkan dengan responden yang sudah tidak bekerja. Bahkan antara responden yang masih bekerja, akan berbeda tingkat aktivitas fisiknya jika dia bekerja sebagai wirausaha yang berdagang dan sebagai buruh. Terutama untuk responden yang bekerja sebagai buruh. Seharihari tentu melakukan aktivitas fisik yang cukup tinggi, apalagi jika pekerjaan buruh yang dilakukan adalah kuli angkut atau sejenisnya yang mencakup kegiatan mengangkat beban yang berat dan berjalan dari satu tempat ke tempat lain untuk mengantarkan barang. Berbeda dengan responden pensiunan PNS atau tidak bekerja. Kemungkinan besar sebagian besar waktu mereka dihabiskan untuk mencari hiburan, seperti menonton TV, bercanda bersama cucu dan keluarga, atau berkebun. Mungkin bagi responden yang tidak bekerja tetapi melakukan kegiatan sukarela seperti menjadi kader posyandu memiliki aktivitas fisik yang lebih besar dibanding responden yang menghabiskan waktu sehari-hari di dalam rumah. Bahkan untuk responden yang berdagang juga terkadang kurang melakukan aktivitas fisik jika yang dilakukan hanya menunggu toko dan hanya bekerja jika ada pembeli.

\section{Gambaran Aktivitas Fisik Responden}

Responden diwawancarai tentang aktivitas fisik yang dilakukan selama satu minggu, mencakup kegiatan sehari-hari yang dilakukan oleh responden dan apabila responden masih aktif bekerja atau melakukan pekerjaan sukarela. Kemudian dilakukan penilaian untuk menentukan nilai aktivitas fisik setiap responden dan digolongkan ke dalam aktivitas cukup dan tidak cukup.

Berdasarkan Tabel 2, sebagian besar responden $(73,5 \%)$ belum melakukan aktivitas fisik yang cukup dalam satu minggu. Sebagian besar responden menyatakan bahwa kurangnya aktivitas fisik yang dilakukan karena rendahnya motivasi untuk melakukan aktivitas fisik yang lebih selain aktivitas fisik standar seperti membersihkan rumah dan memasak. Ditambah lagi fakta bahwa responden adalah lansia, di mana sebagian besar sudah mengalami penurunan fungsi otot, susah melakukan aktivitas fisik yang berat, dan cenderung lebih cepat lelah sehingga waktu mereka sehari-hari dihabiskan dengan menonton TV atau mengobrol bersama keluarga. Beberapa responden masih melakukan aktivitas lain seperti

Tabel 2. Distribusi Responden Berdasarkan Aktivitas Fisik

\begin{tabular}{lcc}
\hline \multicolumn{1}{c}{ Aktivitas Fisik } & n & \% \\
\hline Tidak Cukup & 50 & 73,5 \\
Cukup & 18 & 26,5 \\
\hline Total & 68 & 100,0 \\
\hline
\end{tabular}

berkebun atau mengikuti serangkaian kegiatan di posyandu lansia, akan tetapi kegiatan tersebut hanya dilakukan satu minggu sekali atau beberapa hari sekali. 


\section{Gambaran Konstipasi Responden}

Pengukuran konstipasi pada responden dilakukan melalui wawancara dengan menggunakan kuesioner Constipation Scoring System. Di dalamnya terdapat pertanyaan tentang kuantitas dan kualitas defekasi yang dialami oleh responden selama satu minggu terakhir.

Pertanyaan yang diajukan mencakup frekuensi defekasi responden dalam satu minggu tanpa bantuan laksatif dan bagaimana kualitas defekasi yang dialami. Kualitas defekasi mencakup apakah proses defekasi berjalan lancar, apakah terdapat nyeri saat melakukan defekasi, apakah ada perasaan tidak puas setelah melakukan proses defekasi, apakah terjadi nyeri pada perut saat tidak dapat melakukan defekasi, dan berapa kali responden gagal mencoba proses defekasi. Kemudian dari kuesioner yang telah terisi dilakukan penilaian untuk menentukan nilai konstipasi masing-masing responden.

Berdasarkan Tabel 3, pada 68 orang responden, ditemukan $66,2 \%$ yang mengalami konstipasi dan $33,8 \%$ responden yang tidak mengalami konstipasi. Sebagian besar responden memiliki frekuensi defekasi yang rendah, yaitu kurang dari 3 kali dalam satu minggu. Meskipun seluruh responden menyatakan tidak memerlukan bantuan cairan laksatif untuk membantu proses defekasi, tetapi responden mengaku bahwa mereka mengalami perasaan tidak puas setelah melakukan defekasi. Pada beberapa responden juga didapat informasi bahwa mereka mengalami nyeri pada saat proses defekasi dan mengalami sakit pada perut jika tidak melakukan defekasi sama sekali dalam sehari. Meskipun begitu terdapat juga beberapa responden yang memiliki frekuensi defekasi yang rendah tetapi tidak mengalami masalah lain seperti nyeri, gangguan pada perut, maupun perasaan tidak puas setelah melakukan defekasi. Menurut

Tabel 3. Distribusi Responden Berdasarkan Konstipasi

\begin{tabular}{|c|c|c|}
\hline Konstipasi & n & $\%$ \\
\hline Ya & 45 & 66,2 \\
\hline Tidak & 23 & 33,8 \\
\hline Total & 68 & 100,0 \\
\hline
\end{tabular}

hasil penilaian konstipasi pada responden tersebut didapatkan informasi bahwa baik kuantitas maupun kualitas defekasi sebagian besar responden rendah sehingga dinyatakan bahwa sebagian besar responden mengalami konstipasi.

Tabel 4. Distribusi Responden Berdasarkan Aktivitas Fisik dan Konstipasi

\begin{tabular}{|c|c|c|c|c|c|c|}
\hline \multirow{3}{*}{$\begin{array}{c}\text { Aktivitas } \\
\text { Fisik }\end{array}$} & \multicolumn{4}{|c|}{ Konstipasi } & \multirow{2}{*}{\multicolumn{2}{|c|}{ Total }} \\
\hline & \multicolumn{2}{|c|}{ Ya } & \multicolumn{2}{|c|}{ Tidak } & & \\
\hline & $\mathbf{n}$ & $\%$ & $\mathbf{n}$ & $\%$ & $\mathbf{N}$ & $\%$ \\
\hline Tidak & 41 & 82,0 & 9 & 18,0 & 50 & 100,0 \\
\hline Cukup & & & & & & \\
\hline Cukup & 4 & 22,2 & 14 & 77,8 & 18 & 100,0 \\
\hline
\end{tabular}

\section{Hubungan Aktivitas Fisik dengan Konstipasi pada Responden}

Konstipasi dapat disebabkan oleh beberapa hal, yaitu asupan serat, asupan air, konsumsi obat-obatan, akibat dari penyakit yang diderita atau aktivitas fisik (Yang, et al., 2012).

Berdasarkan Tabel 4, dari seluruh responden, responden yang tidak cukup melakukan aktivitas fisik dan mengalami konstipasi sebesar $82 \%$ dan sebagian besar responden yang cukup melakukan aktivitas fisik sebesar $77,8 \%$ tidak mengalami konstipasi.

Berdasarkan hasil uji statistik Korelasi Spearman, didapat nilai $\mathrm{p}$ sebesar 0,000 di mana $\mathrm{p}<0,1$ yang berarti terdapat hubungan antara aktivitas fisik dengan konstipasi pada responden. Koefisien korelasi yang didapat adalah sebesar 0,557 yang menunjukkan adanya hubungan yang kuat dan bersifat positif di antara kedua variabel tersebut sehingga apabila terdapat peningkatan aktivitas fisik maka meningkat juga kemungkinan untuk terbebas dari konstipasi dan sebaliknya.

Berdasarkan Tabel 4, sebagian besar responden yang mengalami konstipasi sebesar $82 \%$ belum melakukan aktivitas fisik yang cukup. Hal tersebut berarti diperlukan aktivitas fisik yang cukup untuk tidak mengalami konstipasi. Pernyataan ini diperkuat dengan jumlah responden yang tidak mengalami konstipasi sebesar $77,8 \%$ telah melakukan aktivitas fisik yang cukup. 
Aktivitas fisik sebenarnya merupakan salah satu aspek yang tidak dapat lepas dari kehidupan sehari-hari. Salah satu tanda kesehatan adalah adanya kemampuan seseorang untuk melakukan aktivitas fisik seperti berdiri, berjalan dan bekerja. Seringkali karena berbagai hal, seseorang malas bergerak dan melakukan aktivitas sehari-hari. Padahal beraktivitas merupakan salah satu aspek yang penting dalam kehidupan untuk menjaga kesehatan (Muzamil, et al., 2014).

Aktivitas fisik secara umum berarti serangkaian gerakan anggota tubuh akibat kontraksi dan relaksasi oleh otot yang memerlukan energi (Ranggadwipa, 2014). Aktivitas fisik perlu dilakukan untuk melatih kekuatan otot dan menjaga agar otot tidak cepat mengalami penurunan fungsi yang signifikan, terutama pada lansia. Semakin tua seseorang, maka secara otomatis fungsi fisiologis dalam tubuh akan menurun (Siregar, 2004).

Seperti yang telah disebutkan sebelumnya, aktivitas fisik merupakan salah satu aspek dalam hidup yang tidak terhindarkan. Aktivitas fisik bukan hanya yang melibatkan olahraga atau mengangkat beban berat. Mengambil minum, memasak, menyapu, berkebun, mandi, dan kegiatan-kegiatan kecil lainnya sudah dapat dikategorikan sebagai aktivitas fisik (Driesse, et $a l ., 2013)$. Hanya saja yang perlu diperhatikan adalah apakah aktivitas fisik yang telah dilakukan sehari - hari sudah cukup untuk kebutuhan tubuh. Kurang beraktivitas dapat berdampak terhadap beberapa aspek kesehatan yaitu munculnya penyakit kronis dan penyakit degeneratif, salah satunya adalah konstipasi (Chu, et al., 2014). Aktivitas yang kurang akan menyebabkan otot-otot tubuh, salah satunya otot polos usus besar, akan mengalami penurunan fungsi fisiologis sehingga mengganggu proses defekasi. Jika otot polos pada usus besar mengalami penurunan fungsi, maka proses pencernaan tidak akan berjalan seoptimal biasanya. Proses pembentukkan feses di dalam usus besar dan rektum akan terhambat, sedangkan semakin lama feses berada di dalam usus besar maka akan semakin banyak air yang terserap oleh usus besar sehingga feses mengeras mengakibatkan terjadinya konstipasi (Nugroho, 2014).
Aktivitas fisik yang tinggi merangsang otot-otot dalam tubuh untuk beraktivitas (Driessen, et al., 2013). Aktivitas fisik dapat mempengaruhi kinerja tonus otot abdomen, pelvis, dan diafragma sehingga dapat membantu kelancaran proses defekasi. Dengan meningkatnya kinerja otot-otot diatas, gerak peristaltik pada usus besar akan meningkat juga dan memudahkan untuk membantu kelancaran proses defekasi. Selain itu, jika otot-otot tubuh terbiasa digunakan untuk melakukan aktivitas, maka otot akan cenderung mengalami perlambatan penurunan fungsi, tidak terkecuali otot polos pada usus besar. Oleh karena itu, penting untuk membiasakan diri melakukan aktivitas fisik, terutama bagi lansia, karena ketika otot sudah mengalami penurunan fungsi, maka fungsi otot akan sulit dikembalikan seperti semula (Chu, et al., 2014).

Hasil penelitian ini sejalan dengan penelitian yang dilakukan oleh Chu, et al. (2014) yang melakukan penelitian tentang faktor-faktor penyebab konstipasi. Penelitian tersebut menjelaskan bahwa ada beberapa faktor penyebab konstipasi, salah satunya adalah aktivitas fisik yang rendah. Selain itu penelitian serupa juga pernah dilakukan oleh Siregar (2004) yang meneliti eliminasi buang air besar dan faktor yang mempengaruhinya. Pada penelitian lain yang dilakukan oleh Nugroho (2014) tentang aktivitas fisik, konstipasi dan derajat hemoroid, juga disebutkan adanya kemungkinan hubungan antara aktivitas fisik dengan konstipasi, meskipun di dalam hasil penelitian tidak dijelaskan lebih mendalam tentang hubungan tersebut.

\section{KESIMPULAN DAN SARAN}

Kesimpulan dari penelitian ini adalah terdapat hubungan yang cukup kuat dan bersifat positif antara aktivitas fisik dengan kejadian konstipasi pada lansia di Kota Madiun. Hal tersebut berarti jika terdapat peningkatan aktivitas fisik, maka meningkat pula kemungkinan lansia terbebas dari risiko mengalami konstipasi.

Saran yang dapat diberikan adalah perlu diadakannya penelitian lebih lanjut tentang hubungan aktivitas fisik dengan konstipasi pada 
lansia dengan menggunakan desain penelitian yang berbeda agar didapat hubungan sebab akibat. Selain itu perlu dilakukan variasi aktivitas fisik seperti senam, kasti lansia, dan olahraga yang sesuai untuk lansia pada kegiatan posyandu lansia di Kota Madiun setiap minggunya agar lansia terbiasa dan rutin melakukan aktivitas fisik.

\section{DAFTAR PUSTAKA}

Adriani, M. dan Wirjatmadi, B. (2012) Peranan Gizi dalam Siklus Kehidupan. Jakarta: Kencana Prenadamedia Group.

Agachan, F., Chen, T., Pfeifer, J., Reissman, P., Wexner, S.D. (1996). A Constipation Scoring System to Simplify Evaluation and Management of Constipated Patients. Florida : Departement of Colorectal Surgery, Cleveland Clinic Florida.

Azizah, D.N. (2014). Hubungan Asupan Energi dan Aktivitas Fisik dengan Indeks Massa Tubuh pada Remaja Putri di Madrasah Aliyah Almukmin Sukoharjo.(Skripsi yang tidak di publikasikan). Universitas Muhammadiyah Surakarta, Surakarta. Diakses dari http:// eprints.ums.ac.id/32206/12/NASKAH\%20 PUBLIKASI.pdf

Badan Pusat Statistik. (2010). Data Sensus Penduduk 2010. Diakses dari http://www.bps. go.id.

Bappenas. (2014). Statistik Penduduk Lanjut Usia 2014. Diakses dari http://bappenas. go.id/files/data/Sumber_Daya_Manusia dan_Kebudayaan/Statistik\%20Penduduk\%20 Lanjut\%20Usia\%20Indonesia\%202014.pdf

Brown, J. E., Isaacs, J.S., Krinke, U.B., Lechtenberg, E., Murtaugh, M.A., Sharbaugh, C., Splett, P.L., Stang, J., Wooldridge, N.H.(2011). Nutrition Through the Life Cycle. 4th edition. USA: Wadsworth Cengage Learning.

Chu, H., Zhong, L., Li, H., Zhang., X., Zhang, J., Hou, X. (2014). Edpidemiology Characteristics of Constipation for General Population, Pediatric Population and Elderly Population in China. Journal of Gastroenterology Research and Practice, 1-11. Diakses dari http://www. hindawi.com/journals/grp/2014/532734/abs/

Driessen, L.M., Jong, J.C.K. (2013). Preschool Physical Activity and Functional Constipation: The Generation R Study. Journal of Pediatric Gastroenterology and Nutrition, 6(57),
767-774. Diakses dari http://journals.lww.com/ jpgn/Abstract/2013/12000/Preschool_Physical_ Activity_and_Functional.15.aspx

Kementerian Kesehatan RI. (2013). Gambaran Kesehatan Lanjut Usia di Indonesia. Jakarta: Pusat Data dan Informasi Kementerian Kesehatan RI.

Marjan, A.Q., Marliyati, S.A. (2013). Hubungan antara Pola Konsumsi Pangan dan Aktivitas Fisik dengan Kejadian Osteoporosis pada Lansia di Panti Werdha Bogor. Jurnal Gizi dan Pangan, 8(2), 123-128. Diakses dari http:// journal.ipb.ac.id/index.php/jgizipangan/article/ viewFile/7689/5955

Muzamil, M.S., Afriwardi, Martini, R.D. (2014). Hubungan antara Tingkat Aktivitas Fisik dengan Fungsi Kognitif pada Usila di Kelurahan Jati Kecamatan Padang Timur. Jurnal Kesehatan Andalas, 3 (2), 202-205. Diakses dari https:// jurnal.fk.unand.ac.id

Nugroho, S.H.P. (2014). Hubungan Aktivitas Fisik dan Konstipasi dengan Derajat Hemoroid di URJ Bedah RSUD Dr. Soegiri Lamongan. Jurnal Surya, 2(18), 41-50. Diakses dari http://stikesmuhla.ac.id/wp-content/uploads/ jurnalsurya/noXVIII/41-50-Jurnal-Ponco.pdf

Pemerintah Kota Madiun. (2014). Laporan Kinerja Instansi Pemerintah Kota Madiun (LKj) tahun 2014. Diakses dari http://madiunkota.go.id/ index.php

Pratiwi, C.U., Marliyati, S.A., Latifah, M. (2013). Pola Konsumsi Pangan, Aktivitas Fisik, Riwayat Penyakit, Riwayat Demensia, Keluarga dan Kejadian Demensia Pada Lansia di Panti Werdha Tresna Bogor. Jurnal Gizi dan Pangan, 8(2), 129-136. Diakses dari http://download. portalgaruda.org/article.php?article $=149065 \&$ val $=199 \&$ title $=$ POLA $\% 20$ KONSUMSI $\% 20$ PANGAN,\%20AKTIVITAS\%20FISIK, \%20 RIWAYAT\%20PENYAKIT,\%20RIWAYAT $\% 20$ DE M EN S I A \% 20 K E L U A R G A, \% 20 DAN\%20KEJADIAN\%20DEMENSIA $\% 20$ PADA\%20LANSIA\%20DI\%20PANTI\%20 WERDHA\%20TRESNA\%20BOGOR

Ranggadwipa, D.D. (2014). Hubungan Aktivitas Fisik dan Asupan Energi terhadap Massa Lemak Tubuh dan Lingkar Pinggang pada Mahasiswa Fakultas Kedokteran Universitas Diponegoro. (Skripsi yang tidak di publikasikan). Fakultas Kedokteran Universitas Diponegoro, Semarang. 
Sari, A.D.K. (2016). Hubungan Asupan Serat dan Aktivitas Fisik dengan Kejadian Konstipasi pada Lansia di Kota Madiun. (Skripsi). Surabaya: Fakultas Kesehatan Masyarakat, Universitas Airlangga.

Siregar, C.T. (2004). Kebutuhan Dasar Manusia: Eliminasi B.A.B. Universitas Sumatera Utara: Diakses dari http://library.usu.ac.id/download/ $\mathrm{fk} /$ keperawatan-cholina.pdf

Solikhah, N.I. (2011). Hubungan Antara Pola Konsumsi dan Aktivitas Fisik dengan Status Gizi pada Lansia di Panti Sosial Tresna Werdha Unit Abiyoso Yogyakarta. Jurnal
Kesehatan Masyarakat, edisi ? Diakses dari http://download.portalgaruda.org/article. php? article $=123502 \&$ val $=5543$

Washburn, R.A., E. McAuley., Katula, J., Mihalko, S.L., Boileau, R.A.. (1993). The Physical Activity Scale for the Elderly (PASE): development and evaluation. J Clin Epidemiol. 46(2), 153-162. Diakses dari http://www.jclinepi.com/article/ S0895-4356\%2899\%2900049-9/references

Yang, J., Wang, H.P., Zhou, L., Xu, C.F. (2012). Effect of dietary fiber on constipation: A meta analysis. World Journal of Gastroenterology, 18(48), 713-738. 